\title{
Perbandingan Pengaruh Sistem Surveilans Berbasis Elektronik dan Paper Based Terhadap Kompetensi Pencatatan dan Kemampuan Deteksi Risiko Hais oleh Perawat Di Rumah Sakit Awal Bros Batam
}

\author{
Novita Simbolon $^{\mathrm{a}, \mathrm{b}}$, Hema Malini ${ }^{\mathrm{b}}$, Sri Muharni ${ }^{\mathrm{c}}$ \\ ${ }^{a}$ Rumah Sakit Awal Bros, Jl. Gajah Mada Kav. 1 Batam, 29444, Indonesia \\ ${ }^{b}$ Fakultas Keperawatan Universitas Andalas Padang, 25163, Indonesia \\ 'STIKES Awal Bros Batam, 29464, Indonesia \\ email korespondensi: novitabagasta@gmail.com
}

\begin{abstract}
HAIs surveillance is a supervision that includes data collection, analysis, interpretation and dissemination, which is currently developing into an electronic-based approach. This electronic-based surveillance is assumed to be able to provide higher data quality, faster and easier. However, this still needs to be proven further. The purpose of this study was to determine the effect and comparison of paper and electronic based on the system of recording and detecting risk of HAIs. This type of research is quantitative research with Quasi design Pre test - Post test Two Group, with a total sampling of 239 nurses. Methods of collecting data using instruments in the form of questionnaires to measure the nurses' competency and the recording system. As an intervention carried out the implementation of electronic and paper-based surveillance for two weeks at the Awal Bros Batam Hospital. Data analysis was performed using the Wilcoxon Test to test the differences and Mann Whitney to test the effect. The results of the study illustrate the differences in nurses' competencies before and after HAIs surveillance training, illustrating the significant influence on the HAIs recording and detection system before and after the application of electronic and paper based. It is recommended to develop electronic-based software for recording and detecting HAIs systems connected to the Hospital Management Information System (SIMRS).
\end{abstract}

Keywords: HAIs; Electronics based; Paper based; Competency

\begin{abstract}
Abstrak
Surveilans HAIs merupakan pengawasan yang mencakup pengumpulan data, analisis, interpretasi dan diseminasi, dimana pada saat ini berkembang menjadi pendekatan berbasis elektronik. Surveilans berbasis elektronik ini diasumsikan dapat menyediakan kualitas data lebih tinggi, lebih cepat dan mudah. Namun, ini masih perlu dibuktikan lebih lanjut. Tujuan penelitian ini adalah untuk mengetahui pengaruh dan perbandingan dari paper dan elektronik based terhadap system pencatatan dan kemampuan deteksi risiko HAIs. Jenis penelitian ini adalah penelitian kuantitatif dengan design Quasi Pre test - Post test Two Group, dengan total Sampling sebanyak 239 perawat. Metode pengumpulan data dengan menggunakan instrumen berupa kuesioner untuk mengukur kompetensi perawat dan sistem pencatatan. Sebagai intervensi dilakukan penerapan surveilans berbasis elektronik dan paper selama dua minggu di Rumah Sakit Awal Bros Batam. Analisis data dilakukan dengan menggunakan Wilcoxon Test untuk menguji perbedaan dan Mann Whitney untuk menguji pengaruh. Hasil penelitian menggambarkan perbedaan kompetensi perawat sebelum dan sesudah pelatihan surveilans HAIs, menggambarkan pengaruh yang signifikan pada sistem pencatatan dan deteksi HAIs sebelum dan sesudah penerapan berbasis elektronik dan paper based. Direkomendasikan mengembangkan Software agar elektronik based untuk sistem pencatatan dan deteksi HAIs terkoneksi dengan Sistem Informasi Manajemen Rumah Sakit (SIMRS).
\end{abstract}

Kata Kunci : HAIs, Elektronik dan Paper based, Kompetensi 


\section{PENDAHULUAN}

Healthcare associated infections (HAIs), menggantikan istilah infeksi nosokomial, infeksi yang terjadi pada pasien selama perawatan di rumah sakit atau fasilitas kesehatan. HAIs juga termasuk infeksi yang didapat di rumah sakit tetapi muncul setelah pulang dan juga infeksi pada tenaga kesehatan karena pekerjaannya dimana infeksi tersebut tidak ditemukan atau tidak sedang berinkubasi pada saat pasien masuk (World Health Organization, 2011). Bila HAIs tidak ditangani dengan baik oleh pihak manajemen rumah sakit, maka akan berakibat pada ketidakselamatan pasien, sehingga saat ini HAIs masih menjadi permasalahan di hampir seluruh rumah sakit.

Surveilans HAIs merupakan suatu pengawasan melalui proses siklus yang mencakup pengumpulan data, analisis, interpretasi dan diseminasi. Surveilans berguna dalam memantau efektivitas program pencegahan dan pengendalian infeksi yang diperlukan untuk keselamatan pasien dan yang wajib untuk dilaporkan (Duerink, Roeshadi, Wahjono, Lestari, \& Hadi, 2006). Tujuan utama dari surveilans HAIs adalah memberikan data berkualitas yang akan berperan dalam pencegahan dan sebagai sistem peringatan akan terjadinya infeksi (Provincial Infectious Diseases Advisory Committee (PIDAC), 2014).

Surveilans HAIs dapat menggunakan metode tradisional atau sering disebut dengan paper based, ada juga yang menggunakan surveilans berbasis elektronik. Untuk sistem surveilans dengan tradisional mempunyai kelemahan dalam penerapan dan pelaksanaannya salah satunya adalah proses pengumpulan data manual yang memakan waktu dan sumber daya yang banyak (Mahomed, Mahomed, Sturm, Knight, \& Moodley, 2017).
Penerapan pencegahan infeksi di Indonesia, saat ini masih menggunakan cara manual, dimana perawat pengendali infeksi melakukan monitoring dengan metode ceklist terhadap kegiatan yang dilakukan perawat dan tenaga kesehatan. Namun berdasarkan pengalaman, peneliti sebagai perawat pencegahan dan pengendalian infeksi yang bertugas mengawasi kejadian infeksi dan pencegahannya, ada beberapa kegiatan yang gagal di evaluasi dikarenakan pada saat pemasangan alat/ tindakan tidak semua kegiatan bisa diawasi secara langsung. Sehingga walaupun di dalam pelaporannya kejadian HAIs berhasil diturunkan dengan penerapan pencegahan infeksi, namun angka infeksi masih terus ada.

Dalam beberapa tahun terakhir, metode pengumpulan data surveilans infeksi berkembang menjadi pendekatan berbasis elektronik. Surveilans berbasis elektronik adalah alternatif populer yang menyediakan kualitas data lebih tinggi, karena pengumpulan data online otomatis. Metode ini merupakan metode pengumpulan data yang ideal untuk pengawasan, pengumpulan data termasuk pemasukan data langsung ke perangkat elektronik atau ke laman institusi. Pengumpulan data berbasis elektronik lebih efektif, cepat dan lebih murah dibandingkan dengan pengumpulan data berbasis kertas (Provincial Infectious Diseases Advisory Committee (PIDAC), 2014).

Penelitian (Redondo-gonz \& Lucendo, n.d.) berusaha mengembangkan sebuah surveilans berbasis data online melalui website yang dikembangkan khusus untuk input data surveilans. Penelitian ini merekomendasikan dalam persiapan pelaksanaan berbasis elektronik, diharapkan untuk melakukan pelatihan berkesinambungan untuk tenaga kesehatan dalam melakukan input data surveilans. Pelatihan terkait 
pengetahuan, keterampilan dalam identifikasi risiko HAIs perlu diberikan.

Standar Nasional Akreditasi Rumah Sakit (SNARS) maupun Komisi Akreditasi Internasional atau Joint Commission Internasional (JCI) meminta pemenuhan standar pencegahan dan pengendalian infeksi di rumah sakit bahwa untuk pengumpulan data surveilans harus menggunakan sistem manajemen informasi berbasis online. Menurut SNARS dan $J C I$, penggunaan surveilans berbasis online untuk mendukung penelusuran risiko, angka, dan tren pada infeksi yang terkait dengan pelayanan kesehatan serta analisis dan interpretasi data dan presentasi temuannya didukung oleh peran manajemen informasi. Selain itu informasi dan data program pencegahan dan pengendalian infeksi khususnya surveilans infeksi diolah bersama dengan informasi data program peningkatan dan manajemen mutu rumah sakit (International, 2017) dan (Komisi Akreditasi Rumah Sakit, 2017).

Rumah Sakit Awal Bros Batam (RSABB) adalah salah satu Rumah sakit yang berada di Kepulauan Riau (KEPRI) dengan tipe $\mathrm{B}$ yang memiliki jumlah tempat tidur 212 buah. Adapun sistem manajemen informasi yang sudah dilakukan oleh Rumah sakit Awal Bros Batam adalah adanya fasilitas penginputan harian data pemakaian invasif ditiap ruangan seperti data pemasangan ventilator, pemasangan Central Vena Line, pemasangan kateter urine dan operasi serta penginputan jumlah infeksi apabila ada kejadian infeksi.

Bentuk grafik setiap harinya akan otomatis muncul apabila kita ingin mengetahui tren harian ataupun bulanan. Kondisi pengembangan sistem informasi di Rumah sakit Awal bros Batam, masih terlihat sederhana dan belum melingkupi tujuan daripada sistem tersebut. Terlihat sederhana karena masih dalam tahap dokumentasi pemasangan alat harian dan belum sampai kepada penerapan pencegahan infeksi lainnya seperti bundle HAIs dan monitoring lainnya. Namun, pengembangan sistem informasi yang ada di rumah sakit ini memberikan kesempatan dalam pengembangan sistem surveilans berbasis elektronik. Penelitian ini bertujuan melakukan analisis perbedaan pengaruh dari Sistem surveilans berbasis elektronik dan paperbased terhadap kompetensi, pencatatan, dan kemampuan deteksi risiko HAIs oleh perawat.

\section{METODE}

Penelitian ini merupakan penelitian kuantitatif dengan desain Quasi Experiment dengan pendekatan pretestpostest with Two Group design untuk menganalisis pengaruh dan membandingkan sistem surveilans berbasis elektronik dan paper based terhadap sIstem pencatatan dan kemampuan deteksi risiko HAIs oleh perawat di Rumah Sakit Awal Bros Batam. Sampel penelitian ini mengambil seluruh perawat yang ada di RS Awal Bros Batam dengan jumlah 239 perawat yang tersebar di ruang rawat jalan dan ruang rawat inap dengan kriteria: bersedia menjadi responden, memiliki pengalaman kerja $>3$ bulan, bersedia mengikuti pelatihan dan penelitian sampai selesai.

Untuk intervensi, maka peneliti melakukan pelatihan tentang surveilans HAIs kepada seluruh perawat termasuk tentang surveilans berbasis kertas dan elektronik. Kemudian, Peneliti melakukan penerapan surveilans berbasis kertas dan elektronik dengan membagi secara acak untuk ruang rawat inap dan rawat jalan. Ruangan yang ditetapkan sebagai kelompok paper based yaitu rawat inap Ursinia, Ophyris, ICU, UGD, Haemodialisa, Endoscopy, dan Kamar 
operasi, ruangan yang ditetapkan sebagai elektronic based yaitu rawat inap Ramonda, Solandra, Pandoria, Magnolia dan Poliklinik. Pelaksanaan dilakukan selama sebulan, dimana peneliti menggunakan instrumen penelitian berupa kuesioner untuk mengetahui pengetahuan, sikap dan keterampilan perawat dalam kegiatan pencatatan surveilesn HAIs yang berbasis elektronik dan paper based. Penulis juga menggunakan formulir monitoring pencatatan pengisian surveilans HAIs untuk menilai pencatatan dari aspek kesesuaian, kelengkapan dan kemudahan dalam.

Kuesioner yang diberikan akan mengukur 5 hal, yaitu pengetahuan perawat, kompetensi sikap perawat, kompetensi keterampilan perawat, perbandingan kemudahan sistem pencatatan sebelum dan sesudah dilakukan pelatihan, dan kemampuan responden dalam mendeteksi HAIs secara dini melalui bundle HAIs. Dalam penelitian ini, surveilans berbasis elektronik, belum mencakup penerapan software dan belum dikaitkan dengan sistem informasi rumah sakit. Surveilans berbasis elektronik dalam penelitian ini baru mencakup penggunaan komputer sebagai tempat dalam perawat menginputkan data. Keseluruhan instrumen yang digunakan dalam penelitian ini dikembangkan berdasarkan penelaahan literatur yang dilakukan peneliti dan telah dilakukan uji validitas dan reliabilitas. Analisa data dilakukan dengn uji statistik, digunakan uji non parametric melalui uji Wilcoxon untuk data yang berpasangan (pengaruh system surveilans), dan uji Mann Whitney untuk yang tidak berpasangan (menguji perbedaan surveilans HAIs berbasis elektronik dan kertas).

\section{HASIL}

Berdasarkan hasil penelitian didapatkan gambaran data demografi perawat di Rumah Sakit Awal Bros Batam adalah seperti pada tabel 1.1 berikut:

\section{Tabel 1. Distribusi Frekuensi Karakteristik Perawat Berdasarkan Jenis Kelamin, Umur, Pendidikan, dan Lama Kerja $(\mathbf{n = 2 3 9})$}

\begin{tabular}{lcccc}
\hline \multicolumn{1}{c}{ Demografi } & \multicolumn{2}{c}{ Paper Based } & \multicolumn{2}{c}{ Electronic Based } \\
\hline \multicolumn{1}{l}{ fenis } & \% & f & \% \\
Kelamin & & & & \\
Laki-laki & 31 & 29.0 & 19 & 14.4 \\
Perempuan & 76 & 71.0 & 113 & 85.6 \\
\hline Umur & & & & \\
> 30 Tahun & 39 & 36.4 & 37 & 28 \\
$\leq$ 30 tahun & 68 & 63.6 & 95 & 72 \\
& & & & \\
\hline Pendidikan & & & & \\
D3 & 60 & 56.1 & 89 & 67.4 \\
D4 & 1 & 9 & 2 & 1.5 \\
Ners & 46 & 43 & 41 & 31.3 \\
& & & & \\
\hline Lama Kerja & & & & \\
$<$ 1 Tahun & 20 & 18.7 & 18 & 13.6 \\
1 - 3 Tahun & 20 & 18.7 & 28 & 21.2 \\
3 - 5 Tahun & 18 & 16.8 & 32 & 24.2 \\
> 5 Tahun & 49 & 45.8 & 54 & 40.9 \\
& & & & \\
\hline Total & 107 & 44.8 & 132 & 55.2 \\
\hline
\end{tabular}

Tabel 1. menunjukkan bahwa pada kelompok Paper Based dan Elektronik Based didominasi oleh perawat dengan jenis kelamin perempuan dan berlatar belakang pendidikan D3 Keperawatan, sebanyak $56.1 \%$ pada kelompok paper based dan $67.4 \%$ pada kelompok elektronik based. Lama masa kerja perawat didua kelompok umumnya $>5$ Tahun sebanyak $45.8 \%$ pada kelompok paper based dan $40.9 \%$ pada kelompok elektronik based. Umur perawat pada dua kelompok umumnya $\leq 30$ tahun, mayoritas pada kelompok elektronik based sebesar $72 \%$. 
Tabel 2. Gambaran Perbedaan Sistem Pencatatan dan kemampuan deteksi Hais Pada Paper Based dan Electronic Based sebelum dan sesudah $(\mathrm{n}=\mathbf{2 3 9})$ Tahun 2019
Tabel 3. Uji Perbedaan Sistem Pencatatan dan Kemampuan deteksi HAIs pada surveilans Paper Based dan Elektronik Based di RS Awal Bros $(n=239)$ Tahun 2019

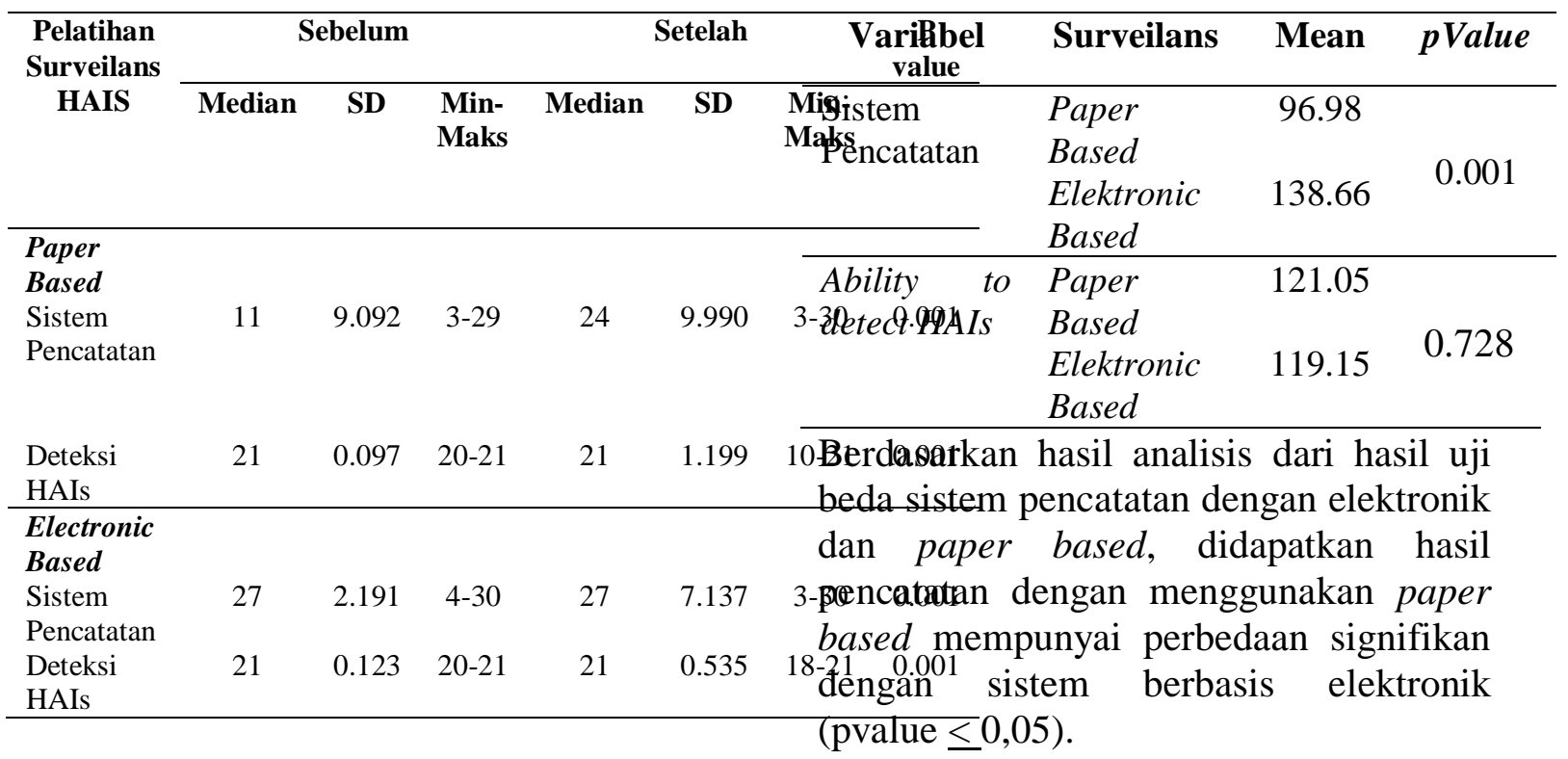

Tabel 2. menunjukkan gambaran pada kedua kelompok untuk system pencatatan dan kemampuan deteksi HAIs, dari surveilans berbasis elektronik dan kertas, sebelum dan sesudah intervensi selama satu bulan. terdapat perubahan secara signifikan pada kedua kelompok. Jika dibandingkan pada kedua kelompok, untuk sistem pencatatan mencakup kesesuaian, kemudahan, dan kelengkapan, maka didapatkan perbedaan mendasar.

\section{PEMBAHASAN}

Pada surveilans berbasis kertas, untuk aspek kesesuaian, menurut responden hanya sekitar 40-60 \% mengatakan bahwa sistem pencatatan paper based ini memiliki salinan laporan yang tepat, konkrit dan akurat serta mendapatkan data yang tepat. Sedangkan bila dilihat dari aspek kelengkapan, $66.4 \%$ responden mengatakan dengan sistem pencatatan, bisa dilakukan dengan lengkap, namun $71 \%$ membutuhkan monitoring atau supervisi yang konsisten dan sangat besar. Hanya sekitar 60\% mengatakan data terkumpul dengan baik dan real, menyimpan informasi dengan lengkap dan menyimpan data pasien dengan terintegrasi. Sementara itu, untuk aspek kemudahan, responden mengatakan dengan sistem pencatatan paper based ini pencatatan yang susah diatur, tidak efisien, menggunakan kertas yang banyak, boros, susah dibaca, membutuhkan waktu yang banyak untuk melakukan pencatatan, dan tidak praktis. 
Pada surveilans berbasis elektronik, dari sistem pencatatan, didapatkan bahwa adanya perubahan pada pengisian kuisioner yang menggambarkan persepsi perawat. Untuk aspek kesesuaian, hampir semua responden (98\%) merasakan bahwa setelah diterapkan sistem pencatatan dengan elektronik, kesesuaian yang dirasakan adalah data yang diisi lebih tepat, pastinya memiliki salinan laporan tepat, data konkrit dan akurat serta dapat mendeteksi data dengan penelusuran histori, Sementara itu, untuk aspek kelengkapan didapatkan bahwa, sebelum penerapan, perawat berpersepsi bahwa sistem pencatatan dengan elektronik akan bisa memberikan sumber data yang tersedia lebih banyak, memberikan informasi yang lengkap, menyimpan arsip agar tidak tercecer serta sistem pencatatan yang terintegrasi.

Setelah diterapkan sistem elektronik, responden merasakan bahwa dari segi kelengkapan, harus mendapatkan pengontrolan yang besar seperti pendampingan dari IPCN atau IPCLN yang bertanggungjawab dalam hal surveilens HAIs, karena sistem ini masih baru walaupun cara pengisiannya sama dengan paper based. Untuk aspek kemudahan, responden mengatakan sistem pencatatan dengan elektronik ini adalah lebih fleksibel dan mudah diatur, tidak memerlukan waktu yang banyak, dan membantu untuk dengan cepat mengidentifikasi tanda-tanda infeksi karena mempunya data yang tersimpan melalui histori pencarian data sebelumnya.

Sistem pencatatan yang menggunakan elektronik akan sukses jika memenuhi beberapa kriteria yaitu akurat, konsisten dan mampu mencatat kejadian setiap waktu. Kelemahan dalam penerapan system berbasis elektronik adalah diperlukan biaya yang tinggi dan ketersediaan personal yang ada setiap saat untuk menganalisis masalah yang terjadi (Woeltje, Lin, Klompas, et al., 2014).

Berdasarkan hasil analisis pengaruh deteksi HAIS dengan paper based, didapatkan bahwa deteksi HAIs dengan paper based mempunyai perbedaan yang signifikan antara deteksi HAIs dengan menggunakan paper based sebelum dan sesudah intervensi ( $\mathrm{p}$ value $=0.001)$. Dari hasil observasi peneliti selama 2 minggu terhadap implementasi pada ruangan yang terpilih menggunakan paper based untuk surveilens HAIs, pada aspek kesesuaian pencatatan pada 41 pasien yang terpasang kateter urine mencapai hanya $65.85 \%$, untuk kelengkapan $28.05 \%$ dan untuk kemudahan sebanyak $23.58 \%$, sementara pada pasien yang terpasang $\mathrm{CVC}$ sebanyak 7 pasien, kesesuaian data mencapai $62.86 \%$, kelengkapan $7.14 \%$ dan kemudahan $14.29 \%$, sedangkan pada pasien yang terpasang ventilator sebanyak dan untuk pasien operasi sebanyak 33 pasien, pencapaian kesesuaian $70.56 \%$, kelengkapan data $18.94 \%$ dam kemudahan $10.10 \%$, sedangkan pada pasien yang terpasang ventilator untuk kesesuaian data $74.75 \%$, kelengkapan mencapai $43.18 \%$ dan kemudahan mencapai 39.3\%. Dilihat dari pencapaian pencatatan surveilans HAIs pada keempat HAIs yaitu ISK, IAD, IDO dan VAP, nilai pencapaan tertinggi dengan menggunakan paper based dari tiga aspek terlihat pada pencatatan pencegahan VAP.

Pelaksanaan sistem pencatatan surveilens dengan menggunakan paper based ditemukan bahwa perawat merasakan formulir pengawasan ini menambah beban kerja mereka, dalam mengumpulkan data tidak konsisten, sementara data harus terisis setiap harinya, begitu juga dengan tim penegndali infeksi tidak mampu secara memadai mengawasi proses tersebut ke 
seluruh ruangan di rumah sakit karena tuntutan pekerjaan yang lainnya.

Ghasemi, Khabazkhoob, Hashemi, Yekta, \& Nabovati (2017) mengatakan dalam penelitiannya bahwa sistem pencatatan surveilans HAIs dengan menggunakan paper based mempunyai kelemahan dalam penerapannya yaitu pengumpulan data yang membutuhkan waktu yang banyak dan membutuhkan sumber daya manusia yang banyak juga. Untuk surveilans berbasis elektronik, berdasarkan hasil analisis pengaruh kemampuan deteksi HAIS mempunyai perbedaan yang signifikan antara deteksi HAIs sebelum intervensi dan sesudah intervensi ( $\mathrm{p}$ value $\leq 0,05$ ).

Dari hasil pengamatan peneliti menggunakan formulir monitoring pencatatan pengisian surveilans HAIs di ruangan yang terpilih menggunakan sistem pencatatan dengan elektronik, didapatkan pengisian pencatatan pada 55 pasien yang terpasang kateter urine menetap yang beresiko terjadinya HAIs ISK adalah dengan tetap menilai dari tiga aspek yaitu kesesuaian, kelengkapan dan kemudahan. Adapun pencapaian kesesuaian data sebesar 98.59\%, kelengkapan $100 \%$ dan kemudahan $100 \%$. Sedangkan untuk kesesuaian pada 8 pasien terpasang CVC yang beresiko infeksi Aliran Darah adalah sebesar 98.21\%, kelengkapan 100\%, dan kemudahan $100 \%$, dan untuk pencatatan pada 77 pasien post operasi yang bersiko infeksi daerah operasi, untuk kesesuaian data mencapai $97.7 \%$, kelengkapan data 97.08\% dan kemudahan sebesar $99.57 \%$.

Dilihat dari hasil pengamatan diatas tampak yang paling lemah ada pada kesesuaian data seperti tanggal pemasangan tindakan invasive tidak sama dengan tanggal sebenarnya, selain itu bundle yang tertulis atau tercatat tidak sesuai dengan penerapan yang ditemukan saat peneliti melakukan observasi. Sedangkan pada kedua aspek kelengkapan dan kemudahan jelas tercapai hamper $100 \%$ dengan pencatatan secara elektronik.

Menurut penelitian Puhto \& Syrjälä (2015) bahwa selama periode pengamatan tercatat angka kejadian HAIs menurun menjadi sekitar $16 \%$. Penelitian ini membuktikan bahwa, sistem surveilans yang berbasis elektronik yang digunakan dan dikaitkan dengan seluruh sistem elektronik di rumah sakit secara terus menerus dapat dilakukan atau diterapkan dalam kegiatan rutin di rumah sakit. Kedepannya diharapkan rumah sakit sudah menerapkan sistem pencatatan berbasis elektronik di semua unit, sehingga data base yang ada lengkap, dan pelacakan pada insinden HAIs .

Berdasarkan hasil analisis dari hasil uji beda sistem pencatatan dengan elektronik dan paper based, didapatkan hasil pencatatan dengan menggunakan paper based mempunyai perbedaan signifikan dengan sistem berbasis elektronik (pvalue $=0.000$ ). Meskipun data yang disimpan dalam sebuah system surveilans berbasis elektronik belum spesifik, namun cukup sensitif dalam hal penyimpanan data dan mudah untuk dikaitkan dengan kebutuhan lain dalam surveilans (Bruin, Seeling, Schuh, 2014).

Sistem surveilans berbasis elektronik meskipun mempunyai kekurangan dalam variabilitas karena sistem ini hanya mengenal satu definisi pengawasan, namun berdasarkan hasil review didapatkan bahwa system elektronik cukup efektif dalam mendeteksi HAIs.

Penggunaan sistem pencatatan elektronik based memerlukan pengontrolan dan pendampingan. Penelitian Mscph et al. (2017) menemukan fenomena dimana sistem surveilans berbasis elektronik mengalami proses yang lambat untuk dapat diterapkan oleh para ICP (Infection Control Person), walau sistem berbasis 
elektronik ini bermanfaat besar. Disinyalir, lambatnya adopsi atau penggunaan sistem otomatisasi surveilans HAIs ini dikarenakan faktor manusia. Teknologi otomatis dalam penelitian ini mengacu pada sebuah proses untuk mendapatkan informasi yang bermanfaat dari database yang besar dan saling berhubungan, salah satunya adalah deteksi insidens HAIs. Para ICP, mengetahui bahwa teknologi ini bisa membantu mereka dalam menjalankan tugas, namun kendala, bahwa mereka harus juga mengerti atau memahami cara mengakses data dari unit lain dan memahami cara kerjanya membuat para ICP merasakan hambatan.

Peneliti menyimpulkan bahwa kendala utama dari penggunaan sistem otomatis/elektronik dalam surveilens infeksi adalah keragu-raguan dalam melaksanakan tugas, tanggung jawab, metode cara kerja, harapan pengguna, menjadi penghambat kenapa adopsi sistem ini lambat. Salah satu upaya dalam mengatasi kondisi keragu-raguan dalam penerapan surveilans otomatis ini adalah dengan lakukan pelatihan yang komprehensif didasarkan pada alur kerja mereka yang menggunakan dan program harus dilakukan dengan tujuan yang jelas. Para ICP harus tahu jenis data apa yang mereka butuhkan, dan bagaimana menggunakan data untuk membuat keputusan (Mscph et al., 2017).

Keengganan sebuah institusi untuk menerapkan sistem berbasis elektronik sebagian dikarenakan kurangnya sumber daya manusia yang akan mengatasi masalah teknis yang muncul dalam penerapan system (Bruin et. Al, 2014). Berdasarkan hasil analisis pengaruh deteksi HAIS dengan paper dan elektronik based, hasil uji statistik didapatkan nilai 0.728 , dimana disimpulkan tidak ada perbedaan yang signifikan antara paper based dan elektronik based dalam mendeteksi
HAIs. Ini bisa terjadi karena, deteksi HAis yang dilakukan lewat bundle HAIs, baik elektronik maupun paper-based, sudah menjadi sebuah kebiasaan.

Menurut Herzig et al., (2016) surveilans HAIs yang dilakukan setiap hari memang menghabiskan banyak waktu, sehingga diharapkan para Infection Control Team beralih pada sistem otomatis surveilans. Ada beberapa hhal yang harus diperhatikan jika sebuah institusi rumah sakit akan menerapkan sebuah system elektronik. Langkah langkah penerapan surveilans dengan berbasis elektronik ini memberikan proses perbaikan dan adaptasi terus menerus sehingga akhirnya sebuah sistem bisa dijalankan dengan baik. Artinya, sistem elektronik yang diberlakukan harus terus disempurnakan untuk mengatasi kelemahan- kelemahan yang ada.

\section{KESIMPULAN}

Penerapan surveilans berbasis elektronik dan berbasis kertas di Rumah Sakit Awal Bros menunjukkan adanya perbedaan pada system pencatatan dan kemampuan deteksi HAIs sebelum dan sesudah intervensi. Hasil perbandingan pada pelaksanaan kedua surveilans ini, untuk system pencatatan ada perbedaan secara bermakna dari segi kemudahan dan kelengkapan. Untuk kemampuan deteksi HAIS, tidak terdapat perbedaan yang bermaknsa, karena pelaksanaan surveilans HAIs di rumah sakit ini sudah efektif diluar metode apa yang digunakan. Masih terdapat banyak kekurangan dalam pelaksanaan surveilans berbasis elektronik, dibutuhkan upaya lanjut agar system ini mampu bermanfaat seperti yang seharusnya.

\section{UCAPAN TERIMA KASIH}

Penulis mengucapkan terima kasih kepada dr. Widya Putri, MARS., selaku 
Direktur RS Awal Bros Batam, Dr. Yulastri Arief, M. Kep., dr. Swesty Sari Suciati, MARS., dan Eka Roza, S.Kep., Terima kasih kepada seluruh responden penelitian yang telah berpartisipasi.

\section{DAFTAR PUSTAKA}

Bruin, J. S. De, Seeling, W., \& Schuh, C. (2014). Data use and effectiveness in electronic surveillance of healthcare associated infections in the 21st century: a systematic review, 942-951. https://doi.org/10.1136/amiajnl2013-002089

National Point Prevalence Survey, 64(May), 61-67. https://doi.org/10.1093/cid/cix103

Gao, F., Wu, Y., Zou, J., Zhu, M., \& Zhang, J. (2015). Impact of a Bundle on Prevention and Control of Healthcare associated Infections in Intensive Care Unit *, 35(2), 283-290.

https://doi.org/10.1007/s11596-015$1425-2$

Ghasemi, M., Khabazkhoob, M., Hashemi, H., Yekta, A., \& Nabovati, P. (2017). The incidence of needle stick and sharp injuries and their associations with visual function among hospital nurses. Journal of Current Ophthalmology, 29(3), 214-220. https://doi.org/10.1016/j.joco.2017.0 6.001

gliquality.org. (n.d.). Manual Paper- based Systems. Retrieved August 22 , 2018 , from http://gliquality.org/sites/default/file s/L2_templates/2.7WHO Paper based LIMS_v1.pdf

Hebert, C., Rn, J. F., Smyer, J., Ascp, M. L. S., Ding, J., \& Mangino, J. E. (2018). American Journal of Infection Control Development and validation of an automated ventilator-associated event electronic surveillance system: A report of a successful implementation. AJIC: American Journal of Infection Control, 46(3), 316-321.

https://doi.org/10.1016/j.ajic.2017.0 9.006

Herzig, C. T. A., Stone, P. W., Castle, N., Pogorzelska-maziarz, M., Larson, E. L., \& Dick, A. W. (2016). Infection Prevention and Control Programs in US Nursing Homes: Results of a National Survey. Journal of the American Medical Directors Association, $\quad$ 17(1), $\quad 85-88$. https://doi.org/10.1016/j.jamda.2015 .10 .017

International, J. C. (2017). Joint Commission International Accreditation Standards for.

Kemenkes RI. (2017). Pedoman 
NERS: Jurnal Keperawatan, Volume 15, No.2, Oktober 2019, (Hal. 74-83)

Pencegahan dan Pengendalian

Infeksi di Fasilitas Pelayanan

Kesehatan. (P. M. K. R. Indonesia,

Ed.) (1st ed.). Jakarta: Kemenkes

Republik Indonesia.

Komisi Akreditasi Rumah Sakit. (2017). STANDAR NASIONAL

AKREDITASI RUMAH SAKIT (1st ed.). Jakarta: Komisi Akreditas Rumah Sakit.

Mscph, K. A., Mt, C. G., Ascp, S. M., Anttila, A., Bsn, J. E. B., Ms, J. N. H., ... Ascp, M. W. M. T. (2017). American Journal of Infection Control Health care-associated infections studies project: An American Journal of Infection Control and National Healthcare Safety Network data quality collaboration. AJIC: American Journal of Infection Control, 45(12), 1394-1395.

https://doi.org/10.1016/j.ajic.2017.0
9.011

Provincial Infectious Diseases Advisory Committee (PIDAC). (2014). Best Practices for Surveillance of Health Care-associated Infections In Patient and Resident Populations (3rd ed.). Ontario: PIDAC.

Puhto, T., \& Syrjälä, H. (2015). Incidence of healthcare-associated infections in a tertiary care hospital: Results from a three-year period of electronic surveillance. Journal of Hospital Infection, 90(1), 46-51. https://doi.org/10.1016/j.jhin.2014.1 2.018

World Health Organization. (2011). Report on the Burden of Endemic Health Care-Associated Infection Worldwide Clean Care is Safer Care. Geneva. 